\title{
CAMPO BELO: NARRATIVA INSUBMISSA E INSURGENTE
}

\author{
Campo Belo: insubmissive and insurgency narrative
}

\section{Geny Ferreira Guimarães}

\author{
https://orcid.org/0000-0003-2147-1197
}

Universidade Federal Rural do Rio de Janeiro, Colégio Técnico da Universidade Rural, Seropédica, RJ, Brasil. 23890-000 - ctur@ufrrj.br

\section{Hildalia Fernandes Cunha Cordeiro}

(D) https://orcid.org/0000-0001-8236-8121

Universidade Federal da Bahia, Instituto de Letras, Salvador, BA, Brasil. 40170-115 coordenacaoppglitcult@gmail.com

\begin{abstract}
Resumo: Neste artigo desejamos provocar e compartilhar reflexões sobre o conto "Isaltina Campo Belo", de autoria de Conceição Evaristo, parte integrante do livro: Insubmissas lágrimas de mulheres. A narrativa escolhida explicita o percurso da personagem em busca de compreensão da sua própria existência. Ao longo do caminho, surgem dúvidas, dores, alegrias e (des)cobertas sobre a construção da identidade de gênero, lesboafetiva e lesboerótica da personagem. O texto foi escrito a partir de alguns encaminhamentos que envolvem: problematizar os silêncios impostos historicamente que são construídos repletos de preconceitos e discriminações sobre a sexualidade da mulher negra; propor a insubmissão e a insurgência como categorias existenciais e claves interpretativas para análise do corpus; buscar referenciais teóricos pertinentes para a compreensão do conto analisado dentro da possibilidade de análise interseccional de gênero e sexualidade, principalmente dialogando com a perspectiva da "epistemologia negra sapatão" de Tanya L. Saunders para o lesbotexto apresentado e de autoras(es) que desenvolvem a perspectiva de pensar a literatura negra epistemologicamente; mapear a jornada da personagem do conto refletindo sobre os seus processos de construção identitária.
\end{abstract}

Palavras-chave: Literatura Negro-brasileira. Mulheres Negras. Lesbotexto. Gênero. Sexualidade.

Abstract: In this article we wish to provoke and share reflections on the short story "Isaltina Campo Belo", by Conceição Evaristo, an integral part of the book: Insubmissas lágrimas de mulheres. The chosen narrative explains the character's journey in search of an understanding of her inner own existence. Along the way, there are doubts, pains, joys and (un)coverings about the construction of the gender identity, lesbian affection and lesbian erotic showed by the character narrative. This article concern a few references about: problematizing historically imposed silences that are built full of prejudices and discriminations about black woman

Esta obra está licenciada sob uma Creative Commons - Atribuição 4.0 
sexuality; propose insubmission and the insurgency as existential categories and interpretative keys for analysis of the corpus; to find relevant theoretical references for the understanding of the tale analyzed within the possibility of intersectional analysis of gender and sexuality, mainly in dialogue with Tanya L. Saunders" "black lesbian epistemology" perspective for lesbian written presented and from who develop the perspective of thinking black literature epistemologically; mapping the journey of the character narrative by reflecting on its processes of identity issues.

Keywords: Black-brazilian Literature. Black Woman. Lesbian Written. Gender. Sexuallity.

\section{Campo Belo: apresente-se!}

O conto Isaltina Campo Belo apresenta um tecer de memórias de uma mulher negra no entendimento sobre si, caminhos, percalços percorridos e enfrentados até compreender-se como lésbica. Momento derradeiro, importante e resultado do longo caminho de dores, dúvidas, violências que a leva a felicidade do reencontro com o seu Eu. Nas suas primeiras linhas encontramos um relato descritivo do encontro de duas mulheres negras e suas experiências que revelam a aproximação feminina negra de amizade e cumplicidade.

A princípio, Isaltina ao relembrar sua trajetória, menciona que acreditava ter um menino dentro de si, dessa forma aproxima a sua narrativa da discussão de gênero. Neste início da leitura, é gerada a expectativa de que se trata de um processo que culminará numa perspectiva transgênero, pois Isaltina vai relatando que sentia um menino dentro de si e sentia uma incompreensão dolorosa porque ninguém ao seu redor conseguia perceber o que ela era e como se sentia, ou seja, não a enxergavam. Até este ponto do conto, nos remete a pensar nas várias construções sociais que foram criadas em torno de gênero, por conta do sexo de nascença que socialmente são impostas condições e funções, comportamentos, papéis que são reconhecidas pelas atividades permitidas aos meninos e homens por um lado e negadas às meninas e mulheres por outro lado.

Na narrativa, a violência que é destinada às mulheres é considerada corretiva, punitiva àquelas que não odeiam, mas que não desejam homens, não se consideram destinadas a serem suas amantes, esposas ou mesmo servas, Campo Belo tem mais do que o seu sentimento e psicológico incompreendido, mas o seu corpo violentado, único lugar verdadeiramente seu. Depois de algum tempo e com a maternidade, Campo Belo começa a compreender que não precisava ser homem para ter o direito de desejar outra mulher, ou o dever de cumprir as determinações sociais vinculadas ao fato de ser mulher, se sentia inteira e lésbica. Percebe que não existia menino algum dentro dela e que poderia ser feliz amando, sendo mãe, mulher e sendo amada. Após tantos enfrentamentos e descobertas compreende que passou uma vida toda para se encontrar e que finalmente consegue conhecer de fato o seu corpo, encontrar-se e sentirse plena e feliz. E, para alcançar isso não foi por meio do afastamento de sua família, nem mudando de cidade ou muito menos mudando de sexo, mas se aproximando e aceitando os seus desejos, sem medo, sem culpas.

O conto escolhido é parte integrante da literatura que consideramos negro-brasileira (CUTI, 2010) e faz parte de rico, complexo e diversificado acervo literário produzido por 
mulheres negras separadas e (re)unidas pelas águas, repletas de memórias do Atlântico, da diáspora africana e da África. Silva (2012) denominará por produção literária afro-feminina. De forma mais ampla esse legado é parte do que Riso ( $\mathrm{s} / \mathrm{d}$ ) intitula de literatura negrodiaspórica. Neste caso, Conceição Evaristo por meio do conto Isaltina Campo Belo apresenta uma escrita negra, feminina e lesboafetiva.

Dito isso, convém salientar, ainda, que decidimos por realizar a leitura e análise da narrativa que Dias (2018) denomina de "afro-lésbica", mas que acabamos substituindo o afro por negro, por questões políticas demarcatórias ${ }^{1}, \operatorname{logo}$, o entendimento neste artigo é por meio da noção negro-lésbica. No mais, a noção usada pela autora permanece e foi indispensável para pensar a narrativa ora estudada e melhor compreender as encruzilhadas, momentos de tomada de decisão e/ou direção, pelas quais passou a personagem em busca do entendimento de si. Não podemos deixar de mencionar as ideias defendidas por hooks $(2006,2000)$ nos textos $O$ amor como prática da liberdade que elege a ética do cuidado de si e do cuidado com o outro e Vivendo de amor como forma de ser e estar no mundo.

Faz-se necessário comentar que, essa não é a primeira narrativa negro-lésbica de autoria de Evaristo. Beijo na face, conto publicado nos Cadernos Negros de número 26 (2003), a autora já trazia tal recorte, o amor entre mulheres. No livro Olhos d'água (2014) além da publicação do conto acima mencionado, há, ainda, o conto intitulado de Luamanda e no penúltimo livro lançado, em 2016, História de leves enganos e parecenças, encontramos o conto, A menina e a gravata. É de bom tom salientar que a discussão de gênero bem demarcada em Ponciá Vicêncio, pelo fato dessa personagem, do romance de mesmo nome, desenvolver um temor cada vez que via um arco-íris por "[...] medo que tivera durante toda a sua infância. Diziam que menina que passasse por debaixo do arco-íris virava menino" (EVARISTO, 2003, p. 13).

A obra, Insubmissas lágrimas de mulheres, foi publicada em 2011 pela editora Nandyala e reeditada pela editora Malê em 2016 (edição comemorativa dos 70 anos da autora). O livro de contos reúne treze histórias de mulheres negras que sofrem os mais diversos tipos de violências e depreciações. Mesmo passando por situações de desprestígio e de profundas adversidades, as personagens conseguem, de alguma forma, alcançar a superação. As histórias são alinhavadas e umedecidas pelas lágrimas derramadas por negras mulheres personagens que se revelam e gritam de um lugar de não submissão e não aceitação a opressão, historicamente, imposta às nós, mulheres negras. Nas palavras da própria autora,

[e]m Insubmissas lágrimas de Mulheres, meticulosamente pensei tudo. Dos nomes à disposição dos contos no livro. Ouvi sim histórias, mas não como a narradora do livro, aquela que se dispôs a sair procurando as histórias de suas semelhantes. Não preciso buscar, elas me buscam, muitas me chegam, fico atenta. Apenas tracei um plano. Eu queria escrever histórias de mulheres, mas não deixando mais minhas parentas sucumbirem à morte. Não as deixaria se degradarem na fome e no desamparo. Passariam por tudo, mas recuperariam a vida. Queria escrever sobre as dores mais profundas dessas mulheres. Queria

\footnotetext{
${ }^{1}$ Para uma melhor compreensão da discussão sobre os prefixos afro e negro ver: FONSECA (2006); CUTI (2010) e a coluna Levantes Literários (indicado nas referências deste artigo).
} 
falar de um sofrimento e de uma carência que não significassem somente a falta do pão, de água ou de teto. Queria escrever sobre mulheres vitoriosas, insubmissas ao destino apesar de... Parece que consegui. (EVARISTO, 2013, $\mathrm{s} / \mathrm{p})$.

O que reafirma o projeto estético, o comprometimento artístico, literário e político que a autora insere na sua escrita e que se enquadra dentro da perspectiva de "escrevivências" (EVARISTO, 2017), mas também da "literatura negro-brasileira" (CUTI, 2010).

Nas páginas a seguir propomos um mergulhar epistemológico no conto Isaltina Campo Belo, mas na verdade, ela representa tantas outras Campos Belos que vivem as mesmas angústias. Para cada subitem do artigo começamos por seu nome "Campo Belo, como gostava de ser chamada" (EVARISTO, 2011, p. 49).

\section{Campo Belo: enfrentamentos, descobertas e felicidade}

Nossos ossos só não andaram expostos porque somos das mulheres que sabem curar. Nossos processos de existência dependem de um cuidado de si que economiza forças de desvio e localização, multiplicidade e identidade estratégica, em uma palavra, (des)territorialização.

Denise Carrascosa (2014)

O que foi a existência da personagem do conto se não um ato ininterrupto de não aceitação das condições impostas? Fossem elas na esfera da construção de gênero, nas elaborações de ordem sexual e no decidir (se é que podemos assim considerar) em ter e criar uma filha que foi fruto de uma violência sexual? Pura insurgência, a mesma resistência na qual fez com que todas as nossas que nos antecederam, não sucumbissem as mais diversas atrocidades cometidas e direcionadas aos nossos corpos e existências ao longo da história da humanidade que sempre procurou nos deixar de fora dessa condição.

As produções teóricas das feministas negras revelam-se indispensáveis para o melhor entendimento da história escolhida e, portanto, a "epistemologia negra-sapatão": como vetor de uma práxis humana libertária" proposta por Saunders (2017) será a fundação e o fundamento para o bom desenrolar do trabalho iniciado. (Re)pensar o lugar da mulher negra e da nossa humanidade, tantas vezes ultrajada ao longo da história, é imprescindível para que possamos alcançar a subjetividade de Campo Belo.

Pensarmos sob a perspectiva da insubmissão e insurgência da personagem é em primeiro lugar apresentarmos o que a leva a ter esse comportamento. Talvez, os enfrentamentos que a atormentam é que a fazem ter esperança de ser reconhecida da forma como se sente. A raiva de não perceberem, as dúvidas sobre o que de fato representa o seu Eu são esforços para que continue acreditando em si mesma. Por tanta incompreensão, Campo Belo se torna insubmissa, caso contrário necessitaria deixar de ser quem é. Luta contra a cegueira de todos que a rodeiam.

Segundo Sales (2017) é preciso encarar a insubmissão como "ato de coragem, desobediência e rebeldia aos regimes de opressão e subjugação racistas, sexistas". E diz: "A insubmissão de mulheres negras tem gerado um conjunto e saberes e ensinamentos essenciais que vão influenciar a condução dos mais distintos processos organizativos e lutas 
contemporâneas".

\section{Campo Belo: sua insubmissão e narrativa nos ajuda a pensar}

Nascimento (2017) propõe a poesia como episteme, como espaço de produção de significado e conhecimento - inspirada em Audre Lorde (poeta feminista lésbica negra). Tomando por base essa premissa, procuramos avançar um pouco mais e pensar na produção literária de mulheres negras espalhadas pela diáspora, se lembrarmos o significado dessa palavra por "o semear adiante" para Walker, S. (2018) capaz de reunir pelas águas do Atlântico as "visões ancestrais do mundo as quais se adaptaram as culturas de outros para criar novas fusões dinâmicas" (WALKER, S., 2018). Nesse contexto, o que se denomina de diáspora negra será concebida e pautada na ideia de Gilroy (2001) que também discute dentro da perspectiva etimológica da palavra:

[a] palavra diáspora está intimamente ligada à noção do semear. Esta herança etimológica é um legado incerto e uma benção imprecisa. Demanda que nos esforcemos por entender o significado do processo de dispersão em oposição à suposta uniformidade daquilo que foi disseminado. A diáspora nos apresenta tensões importantes entre o aqui e o agora, o antes e o depois, entre a semente que está guardado no pacote, na bolsa ou no bolso e a semente que se espalhou no chão, no fruto ou no corpo. (GILROY, 2001, p. 125).

Assim, as escritas negrodiaspóricas foram e ainda são construídas pela memória das águas rubro-negro, noção que surge em analogia ou metaforicamente com relação ao "Atlântico Negro" (GILROY, 2001) que vez por outra se vê tingindo de rubro, como o sangue derramado, ontem e ainda hoje, nessas barcas abertas como sinalizou Glissant (2010, 2011). Embarcações diversas que transportaram, via translado, seres humanos que seriam escravizados e mantidos em condições sub-humanas, criando, solidificando e propagando o que veio a se configurar como uma "memória inconsciente do abismo". Diz Glissant (2011, p. 20) sobre isso:

[a] experiência do abismo está no abismo e fora dele. Tormento daqueles que nunca saíram do abismo: que passaram diretamente do ventre do navio negreiro para o ventre violeta dos fundos do mar. Mas a sua provação não morreu, vivificou-se nesse contínuo-descontínuo: o pânico do país novo, a saudade da terra perdida, e por fim a aliança com a terra imposta, sofrida, redimida. A memória não sabida do abismo serviu de lodo para essas metamorfoses. Os povos que então se constituíram, mesmo que tivessem esquecido o abismo, mesmo que não conseguissem imaginar o tormento daqueles que aí pereceram, não deixaram de tecer uma vela (um véu) com a qual, não regressando à Terra-Anterior, se ergueram nesta terra aqui, súbita $\mathrm{e}$ estupefacta. Encontraram nela os primeiros ocupantes, também eles deportados por um saque imóvel. Ou então adivinharam apenas os seus vestígios devastados. Terra da além tornada terra em si. E essa vela desconhecida, que por fim se desfralda, é irrigada pelo vento branco do abismo. E assim o desconhecido-absoluto, que era a projeção do abismo, e que transportava eternamente o abismo-matriz e o abismo infinito, tornou-se por fim conhecimento. (GLISSANT, 2011, p. 20) 
São essas mesmas águas que, já há algum tempo, se expandem para outros oceanos, não só o Atlântico, via processos migratórios históricos do período colonial, mas também via globalização que ora separa, ora (re)une este mesmo povo, diverso e múltiplo, ainda por errância, exílio, perdas e com base em Haesbaert (2007), por meio de processos de desterritorialização e reterritorialização territoriais, individuais e coletivas. Compreendemos que o processo de desterritorialização seria um contínuo de dinâmicas territoriais. Desta forma podemos pensar a diáspora africana considerando o sequestro e a partida de África, que incluiu o deslocamento compulsório de africanos pela travessia Atlântico Sul enquanto uma desterritorialização e, o desembarque, assim como o fincar raízes em outras terras para representar a reterritorialização. Neste caso, nos remete a multiterritorialidades, justamente por se tratar da diáspora como um processo que alcançou vários territórios não apenas o americano. O que Walker, S. (2018) apresenta por meio dos "rostos familiares" da diáspora, ou seja, negros de ascendência africana que podem ser encontrados em toda parte do mundo.

Se essas águas do Atlântico separaram e espalharam corpos e existências, são elas, novamente, que (re)unem vozes e reivindicações, que ainda giram em torno de respeito e dignidade, citando as artes literárias como um dos meios para isso. Seguindo essa metáfora mais do que significativa e emblemática, da memória das águas, coadunamos com Augusto (2017, p. 31) quando esta declara que "A língua não deve nos separar". Assim, a tradução e circulação das obras literárias de mulheres negras pela diáspora revela-se como fundamental para "organizar e fazer o levante", como sinaliza Carrascosa (2017), a organizadora do livro Traduzindo o Atlântico Negro. É desta autora, Carrascosa (2017) a noção de "gerenciamento bioafetivo político das subjetividades" e que é útil, também, para compreender o caminho percorrido por Campo Belo, rumo a ser o que se é, ou seja, uma mulher lésbica. Entendemos, a própria personagem como sujeito da sua própria vida e história, autogerenciando o seu corpo e a sua sexualidade é capaz de decidir por onde passam e passeiam seus afetos, desejos e, de maneira positiva, como se enxerga no espelho.

Comparando com os "bons espelhos", mencionados por Lorde (2000) e que a autora afirma serem nada baratos, com o Abẹbẹe, ferramenta litúrgica constituída por um leque e espelho, aquele que nos apresenta referências primeiras e positivas é que nos faz pensar a potência que a escrita de mulheres negras espalhadas e (re)unidas pelas negras águas atlânticas, revelam, com mais nitidez, precisão e coerência, nossos processos de (re)vermo-nos, (re)elaborarmo-nos e (re)fazermo-nos, objetivando tornarmo-nos o que somos. Lorde (2007, p. 43) denominará tal complexo processo de "autodefinição" e Evaristo (2005) muito próximo a tal noção denominará de "auto-apresentação" que apresenta as mulheres negras como

[...] invibilizadas, não só pelas páginas da história oficial brasileira, mas também pela literatura, e quando se tornam objetos da segunda, na maioria das vezes, surgem ficcionalizadas a partir de estereótipos vários, para as escritoras negras cabem vários cuidados. Assenhorando-se "da pena", objeto representativo do poder falo-cêntrico branco, as escritoras negras buscam inscrever no corpus literário brasileiro imagens de uma autorepresentação. Surge a fala de um corpo que não é apenas descrito, mas antes de tudo vivido. 
A escre(vivência) das mulheres negras explicita as aventuras e desventuras de quem conhece uma dupla condição, que a sociedade teima em querer inferiorizada, mulher e negra (EVARISTO, 2005, p. 205, grifo da autora).

Buscando acompanhar e seguir o fluxo e ritmo das águas das inúmeras travessias como poética, Glissant (2005, p. 17) por meio do "migrante nu" nos ajudará a ilustrar tamanho terror, pois ele conseguiu desenhar as atrocidades que ainda vaga, latente, tanto em nossas memórias e corpos quanto nas "águas-lembranças" (EVARISTO, 2017, p. 11) das inúmeras travessias que ainda temos que enfrentar, cotidianamente, em busca, então, de respeito e dignidade. Sobre o abismo, Édouard Glissant apresenta que

[n]avegando no esplendor verde do mar [...] ainda me vem à mente, vindo à luz como algas marinhas, essas profundezas mais baixas, essas profundezas, com a pontuação de bolas e correntes escassamente corroídas. Na verdade, o abismo é uma tautologia: todo o oceano, o mar inteiro desmoronando suavemente no final, nos prazeres da areia, formam um vasto começo, mas um começo cujo tempo é marcado por essas bolas e correntes que se tornaram verdes. [...] Eles não acreditam que estão dando origem a qualquer força moderna. Vivem a Relação e abrem caminho para isso, na medida em que o esquecimento do abismo lhes incide e que, conseqüentemente, sua memória se intensifica.

Pois, embora essa experiência tenha feito você, vítima original de flutuar em direção aos abismos do mar, uma exceção, tornou-se algo compartilhado e nos fez, os descendentes, um povo entre outros. Os povos não vivem com exceção. A relação não é composta de coisas estranhas, mas de conhecimento compartilhado. Esta experiência do abismo pode agora ser considerada o melhor elemento de troca. (GLISSANT, 2010, p. 7-8, tradução nossa).

A narrativa no conto Isaltina Campo Belo é concebida aqui como parte constituinte da noção "Literatura Abẹbẹ". Tal noção surge da necessidade de conceber a nossa produção literária a partir dos nossos valores e princípios, pensada, principalmente a partir da incitação/provocação, intimação que legitime e visibilize a literatura feita por mulheres negras pela diáspora na busca de rotas de fuga e esquiva do racismo e tentativas diversas de aniquilamento do nosso psíquico. Ao longo da leitura, nós encontramos caminhos de insubordinação e insurreição contra tais processos.

E novamente, Lorde (2007) menciona sobre a necessidade e urgência de acessarmos e conhecermos as especificidades do nosso íntimo, declarando que "poesia não é luxo":

[p]ara cada uma de nós, mulheres, há um lugar escuro por dentro, onde escondido e crescente o nosso espírito verdadeiro se ergue, "bonito/e firme como uma castanha/opondo-se colunar ao (v)nosso pesadelo de fraqueza" e impotência.

Esses lugares de possibilidade dentro de nós são escuros porque são ancestrais e escondidos; eles têm sobrevivido e crescido fortes através daquela escuridão. Dentro desses lugares profundos, cada uma de nós mantém uma reserva incrível de criatividade e poder, de emoção e sentimento não examinado e não registrado. O lugar de poder de mulher dentro de cada uma de nós não é branco nem superfície; é escuro, é ancestral, e é profundo (LORDE, 2007, 


$$
\text { p. 36-37, grifo nosso/tradução nossa). }{ }^{2}
$$

Será ela, também, a que nos convida a pensar que podemos transformar o nosso silêncio, fruto quase sempre do medo, em linguagem e ação e levar em consideração a potência que é o uso do erótico, que se aproxima de Souza (1983) quando declara:

A descoberta de ser negra é mais que a constatação do óbvio [...] Saber-se
negra é viver a experiência de ter sido massacrada em sua identidade,
confundida em suas perspectivas, submetidas a exigências, compelida a
expectativas alienadas. "Mas é também, e, sobretudo, a experiência de
comprometer-se a resgatar sua história e recriar-se em suas
potencialidades (SOUZA, 1983, p. 17, grifo nosso).

Vemos, dessa forma, que para além de guardiães das nossas memórias como muitas das nossas se configuram, sobretudo as mais velhas, somos, também, aquelas que criam e propagam novas, restauradoras e performáticas narrativas, histórias e memórias sobre as nossas vivências e experiências e move, muitas vezes, para além da dor, compartilhando histórias de amor, superação e vitórias. Concebe-se aqui, também, a escrita como possibilidade de condensar os processos vivenciados, bem como o compartilhar de tais experiências e dos saberes adquiridos a partir delas.

Não podemos deixar de mencionar que a insubmissão, a insubordinação e a insurgência são concebidas, nesse acervo herança, como categorias de análise, claves fundamentais para a interpretação não só do corpus, mas concebendo-as como um traço presente e marcante nessa "Literatura Abẹbẹ", pois, nas palavras de Evaristo (2007), um ato de insubordinação é do que trata tal "escrita-empreendimento", uma vez que: “[...] Em se tratando de um ato empreendido por mulheres negras, que, historicamente, transitam por espaços culturais diferenciados dos lugares ocupados pela cultura dominante, escrever adquire um sentido de insubordinação" (EVARISTO, 2007, p. 20-21, grifo nosso).

A narrativa que se configura como corpus nesse artigo enquanto uma Literatura Abẹbè nos faz compreender a potência que essa escrita de mulheres negras e em especial aqui o lesbotexto de Evaristo apresenta como ferramenta indispensável nos processos de (auto)conhecimento, mas como instrumento que além de apontar caminhos e possibilidades de insurreição e esquiva contra a nefasta ideologia da branquidade, acaba auxiliando, sobremaneira na cicatrização e cura de nossas feridas, principalmente aquelas concebidas como narcísicas por Souza (1983), feridas essas muito próximas ao que hooks (2000) já sinalizava, interrogando, sobre nossa tensa e conflituosa relação com o espelho e a imagem que vemos refletida nele:

Onde está o amor, quando uma mulher negra se olha e diz: Vejo uma pessoa feia, escura demais, gorda demais, medrosa demais - que não merece ser

\footnotetext{
2 "For each of us as women, there is a dark place within, where hidden and growing our true spirit rises, "beautiful/and tough as chestnut/stanchions against (y)our nightmare of weakness/" and of impotence.

These places of possibility within ourselves are dark because they are ancient and hidden; they have survived and grown strong through that darkness. Within these deep places, each one of us holds an incredible reserve of creativity and power, of unexamined and unrecorded emotion and feeling. The woman's place of power within each of us is neither white nor surface; it is dark, it is ancient, and it is deep." (LORDE, 2007, p. 36-37).
} 
amada, porque nem eu gosto do que vejo. Ou talvez: Vejo uma pessoa tão ferida, que é pura dor, e não quero nem olhar pra ela porque não sei o que fazer com essa dor. Aí o amor está ausente. Para que esteja presente, é preciso que essa mulher decida se olhar internamente, sem culpa e sem censura. (hooks, 2000, p. 196, grifo da autora).

Eis a potência para onde apontam essas escritas de mulheres negras, o despontar, o cicatrizar e o curar de tantas mazelas acumuladas nesta corporalidade. Ainda que muitas vezes sejam memórias ficcionalizadas das nossas existências, são quase sempre, "escrevivências" (EVARISTO, 2017), ou seja, nas palavras da própria autora:

escrita profundamente comprometida com a vida, escrita profundamente comprometida com a vivência. Mesmo que seja em um processo de ficcionalização e ficcionalizar a partir dos fatos, de situações reais que podem ser da minha vivência ou não. Que podem ser da minha história particular. Que podem ser da minha história coletiva. Sempre uma escrita marcada pela minha condição da minha vivência de mulher negra na sociedade brasileira. (EVARISTO, 2017).

Temos acesso e conhecimento que muitas mulheres passam por agruras e demandas muito parecidas e não sucumbiram, pois vencem, superam e ainda deixam marcas para que outras conhecê-las. A multiplicidade de histórias vivenciadas e experienciadas pelas nossas sistas é que nos levam a propor a noção de "Literatura Abẹbẹ". Uma vertente literária que se mira em referências ancestrais e que inevitavelmente aponta para um futuro com muito mais dignidade para todas nós e um presente pleno de possibilidades.

Elegemos como princípios que banham e sustentam este artigo, bem como a noção acima mencionada, a "Literatura Abẹbẹ", o "womanism" proposto por Walker, A. (1983, p. xi) e a noção de "comunidade de experiência narrativizada" (GIRAUDO, 1997, p. 68). A partir dessas contribuições teóricas que passamos a conceber e explorar as narrativas das mulheres negras espalhadas e (re)unidas pelas águas memórias do atlântico rubro-negro e pelo amor.

Giraudo (1997) denominará de "comunidade de experiência narrativizada" o compartilhamento de experiências narradas que sejam capazes de formar uma rica, complexa e diversa colcha de retalhos. Estas, poder ser comparadas com as mesmas que nossas bisavós, avós e mães criavam. Gerações de mulheres que por razões diversas não conseguiram ter acesso à escola, educação formal e a escrita, mas que nem por isso deixaram de pensar e significar o mundo, de simbolizá-lo e organizá-lo, dentre das possibilidades existentes. Walker, A. (1985) novamente nos apresenta a sobre essas múltiplas possibilidades de atribuir sentidos e significados ao vivido, quase sempre arduamente. Diz ela:

[e]u percebo que é só quando minha mãe está mexendo em suas flores que ela está radiante, até o ponto de tornar-se invisível - menos como criadora: mão e olho. Ela está envolvida no trabalho de que sua alma precisa. Ordenando o universo segundo a imagem de sua própria concepção de beleza.

Seu rosto enquanto prepara a arte que é seu dom, é um legado de respeito que me deixa, pois isso tudo ilumina e encarece a vida. Ela tem passado adiante o respeito pelas possibilidades - e a vontade de aproveitá-las. 
Para ela, tão limitada e espezinhada de tantas maneiras, ser uma artista tem sido ainda assim parte diária de sua vida. Essa capacidade de seguir em frente, mesmo por meios muito simples, é um trabalho que as mulheres negras têm feito por muito tempo. (WALKER, A., 1985, p. 2380, grifo nosso).

Se várias gerações de mulheres negras não puderam acessar a escrita como forma de compartilhar suas histórias, essas mesmas gerações mais velhas sempre buscaram formas alternativas, as mais diversas, de socializar suas experiências, quer fosse costurando colchas com sobras de panos, de tecidos, quilt/patchwork, quer fosse planejando e construindo jardins, seus ou das casas nas quais trabalhavam, dentre tantas outras possibilidades de expressão e arte. As mulheres negras, ao longo da história, buscaram, sempre, formas de organizar e expressar suas vivências e experiências e a narradora da obra ora analisada sinaliza na epígrafe que antecede as treze narrativas que compõem o livro:

[i]nvento? Sim, invento sem o menor pudor. Então, as histórias não são inventadas? Mesmo as reais, quando são contadas. Desafio alguém a relatar fielmente algo que aconteceu. Entre o acontecimento e a narração do fato, alguma coisa se perde e por isso se acrescenta. O real vivido fica comprometido. E, quando se escreve, o comprometimento (ou o não comprometimento) entre o vivido e o escrito aprofunda mais o fosso. Entretanto, afirmo que, ao registrar estas histórias, continuo no premeditado ato de traçar uma escrevivência. (EVARISTO, 2011, p. 9)

Percebe-se que se trata de saberes, dizeres e fazeres em diferentes partes do mundo, tão próximos e necessários. Enfim, o empenho em passar adiante as aprendizagens do, quase sempre, duramente vivido é garantido pelas mais diversas possibilidades de fazê-lo. Gerações inteiras passam a ter onde mirar-se e melhor compreender o que precisam fazer para seguir adiante sem sucumbir, uma vez que as mais velhas, as que nos antecederam deixaram marcados e registrados os seus passos a serem seguidos.

As referências, ancestrais ou não, foram apresentadas e oferecidas para as que vieram depois e que, ainda hoje, sempre insubmissas, insubordinadas e insurgentes, sobretudo ao poder patriarcal e falocêntrico branco, lutam por respeito e dignidade sobre nossos corpos e existências.

\section{Campo Belo: costurando a vida com fios de ouro}

Enquanto as irmãs negras não gostam de ouvir isto, eu teria que dizer que todas as mulheres negras são lésbicas, porque fomos criadas nos restos de uma sociedade basicamente matriarcal, não importa quão oprimidos que pode ter sido pelo patriarcado.

Audre Lorde (1983)

Nesta parte do artigo, a intenção é mapearmos e partilhar trechos significativos do conto escolhido que, além de apresentar parte do enredo, acaba, auxiliando, também, na compreensão das estratégias narrativas utilizadas pela autora no intuito de conhecermos e acompanharmos a construção identitária da personagem, Isaltina Campo Belo, permeada de dúvidas, anseios, e (des)cobertas em seus processos de compreensão de si. Conheçamos então as histórias e 
memórias da personagem.

No que diz respeito ao lugar de fala de Campo Belo e no que se refere ao seu pertencimento etnicorracial, encontramos os seguintes trechos:

Campo Belo, como gostava de ser chamada, dentre outros detalhes, tinha uma idade indefinida, a meu ver. Se os cabelos curtos, à moda black-power, estavam profundamente marcados por chumaços brancos, denunciando que a sua juventude já tinha ficado há um bom tempo para trás, seu rosto negro, sem qualquer vestígios de rugas, brincava de ser o de uma mulher, que no máximo teria os quarenta anos. [...] Éramos muito conhecidos e bem aceitos. Nossa família, desde os avós maternos de minha mãe já se encontrava estabelecia na cidade. Eles tinham chegado ali, como negros livres, nos meados do século XIX, com uma parca economia. Minha mãe, orgulhosamente, sempre nos contava a luta de seus antecedentes pela compra da carta de alforria. Histórias que eu, meu irmão e minha irmã ouvíamos e repetíamos com altivez, sempre que podíamos, na escola. Meu pai, também nascido e ali criado, tinha mais histórias mais dolorosas de seus antepassados de seus antepassados. Entretanto, seus pais, meus avós, à custa de muito trabalho em terras de fazendeiros, em um dado momento, conseguiram comprar alguns alqueres de terra e iniciaram uma lavoura própria. Era uma narrativa que alimentava também a nossa dignidade. (EVARISTO, 2011, p. 49-50, grifo nosso).

Alguns outros trechos explicitam momentos vividos pela personagem permeados de angústias, dúvidas e medos, sobretudo no que diz respeito ao gênero e sexo, tais como: "[c]omo meu irmão não percebia que eu era igual a ele e como a minha irmã não percebia que eu era diferente dela? (EVARISTO, 2011, p. 52, grifo nosso) ou "[o]utro acontecimento que marcou a minha vida, no que tange ao menino que eu acreditava trazer em mim, foi quando surgiram os primeiros sangramentos menstruais de minha irmã", bem como no trecho: "[e]u sabia, desde a infância, do menino que existia em mim. E esse menino crescera comigo, assim como cresceram os meus seios" (EVARISTO, 2011, p. 55, grifo nosso).

Em alguns momentos da narrativa, a sistemática construção de gênero, e a constante fiscalização para com a mesma, aparecem de forma explícita revelando que se trata de um processo, de um constructo social:

[m]amãe veio ralhando contra o meu escândalo e ordenando que descêssemos da árvore, (aliás, ela não gostava que subíssemos em árvores, só o meu irmão podia. [...] Mamãe nos mandou entrar. Fomos os três. Entretanto, meu irmão foi dispensado e avisado de que não ficasse por ali, tentando escutar conversa de mulheres. Sem muito rodeio e grandes explicações, ela nos falou do sangue que as mulheres vertem todos os meses. (EVARISTO, 2011, p. 53, grifo nosso).

Paralela à construção de gênero, há ainda um investimento, enquadramento e vigilância no que diz respeito ao processo que Rich (2010) denominará de "heteronormatividade compulsória". Vejamos algumas dessas passagens que acabam revelando a sistemática tentativa da sociedade em regular as possibilidades de exercer as sexualidades: "[e]u, até então, encarava o estupro como um castigo merecido, por não me sentir seduzida por homens." 
(EVARISTO, 2011, p. 57, grifo nosso) e nos trechos:

[s]em nada para contar, pois nada eu tinha vivido nesse terreno, estranha no ninho, e que os pares são formados por um homem e uma mulher, resolvi sair de casa, mudar de cidade, buscar um mundo que me coubesse. [...] Ele de uma elegância e de um cuidado tal, que adquiriu a minha confiança. E me conquistou tanto como uma pessoa de bem, que acreditei que ele entenderia, quando eu contasse para ele uma das diferenças que eu vivia em mim, em relação ao nosso namoro. Um dia, em que ele desejava beijos e afagos, e eu sem desejo algum, sem nada a me palpitar por dentro e por fora, falei de minha vida até ali. [...] Ele sorrindo, dizia não acreditar e apostava que a razão de tudo deveria ser algum medo que eu trazia escondido no inconsciente. Afirmava que eu deveria gostar muito e muito de homem, apenas não sabia. Se eu ficasse com ele, qualquer dúvida que eu pudesse ter sobre o sexo entre um homem e uma mulher acabaria. Ele iria me ensinar, me despertar, me fazer mulher. (EVARISTO, 2011, p. 54-55, grifo nosso).

Há, ainda, a aposta na construção da masculinidade, explicitada abaixo, e as formas de violência existentes que acreditam assegurar que a mesma permaneça como hegemônica. $\mathrm{O}$ estupro narrado vem em tom de denúncia e não aceitação, como não poderia deixar de ser:

[n] unca poderia imaginar o que me esperava. Ele e mais cinco homens, todos desconhecidos. Não bebo. Um guaraná me foi oferecido. Aceitei. Bastou. Cinco homens deflorando a inexperiência e a solidão do meu corpo. Diziam, entre eles, que estavam me ensinando a ser mulher. (EVARISTO, 2011, p. 56, grifo nosso).

Antes de apresentar o desfecho da história, a autora sinaliza, em muitos momentos, uma aproximação e possibilidade da protagonista Isaltina Campo Belo ser um homem trans, ou pelo menos cria uma expectativa de leitura nessa direção. Vejamos algumas dessas passagens: "[s]eus dias seguiam tranquilos. Eu era eu, uma moça a esconder um rapaz, que eu acreditava existir em mim." ou "[...] foi então que o menino que habitava em mim reapareceu crescido" (EVARISTO, 2011, p. 57, grifo nosso) ou:

[e]u me sentia menino e me angustiava com o fato de ninguém perceber, tinham me dado um nome errado, me tratavam de modo errado, me vestiam de maneira errada... estavam todos enganados. Eu era um menino. O que mais me intrigava era o fato de minha mãe ser enfermeira e nunca ter percebido o engano que todos cometiam. Ainda novinha, talvez antes dos meus cinco anos, eu já descobrira o menino que eu trazia em mim e acreditava piamente que um dia, os grandes iriam perceber o erro que estavam cometendo. [...] E, quando, aos seis anos, numa noite, fui acometida por uma grave crise de apendicite, tendo de ser levada às pressas para o hospital, intimamente sorria feliz. Enquanto eu imaginava a minha volta como menino e a surpresa que isso causaria, meu irmão e irmã choravam copiosamente, pensando que eu fosse morrer. [...] O médico iria descobrir quem era eu, lá por debaixo de mim, e contaria para todos. Então, o menino que eu carregava e que ninguém via, poderia soltar as suas asas e voar feliz. (EVARISTO, p. 50-51, grifo nosso).

[...] Lembro-me que fui invadida por certo sentimento, que não sei explicar 
até hoje, uma sensação de estar fora de lugar. Eu via e sentia o meu corpo parecer com o de minha irmã e se diferenciar do porte de meu irmão. Eu já sabia que a história do sangue menstrual era nossa, isto é, de mulheres. (EVARISTO, 2011, p. 53, grifo nosso).

O que se pode notar é que até compreender-se lésbica, Campo Belo tinha a convicção de que trazia um menino dentro de si e cresceu alimentando tal crença. Será essa uma estratégia de construção narrativa elaborada pela autora para adiar e surpreender ao final com o entendimento da protagonista de que era lésbica? Induzir o leitor a pensar a mesma como um homem trans? Uma pauta ainda tão pouco discutida em nossa produção literária.

A escrita acaba servindo, também, como possibilidade de denúncia dos mais diferentes tipos de violência pautadas no patriarcalismo, com isso, a severa crítica ao mesmo na tentativa de quebra com os estereótipos. Além da cena de violência sexual sofrida pela personagem, temse: "[...] e afirmava com veemência, que tinha certeza de meu fogo, pois, afinal, eu era uma mulher negra, uma mulher negra... Eu não sabia o que responder para ele" (EVARISTO, 2011, p. 55, grifo nosso). Nesse trecho é possível perceber que Evaristo apresenta de forma crítica o caráter estereotipado social de que a mulher negra encontra-se sempre disponível e sedenta por sexo; a hiperssexualidade. Como se essa fosse característica inata da mulher negra. A construção estabelecida socialmente é que torna-se inconcebível pensar essa corporalidade sem uma sexualidade sempre exacerbada, criando e propagando, no imaginário social. Dessa forma, uma imagem e representação de uma mulher negra como corpo de uso, sempre sedenta e disponível para o sexo.

A autora deixa para o final da história a compreensão da personagem e aceitação de ser lésbica, não mais "uma menina com um menino dentro de si", mas sim uma mulher que sente desejo por outra mulher. No desfecho, momentos de (auto)percepção são expostos: "[e] foi então que eu me entendi mulher, igual a todas e diferente de todas que ali estavam" (EVARISTO, 2011, p. 58, grifo nosso) e de (auto)descoberta:

[n]esse emaranhado de lembranças, lá estavam o meu corpo-mulher, a cena do estupro, minha filha nascendo. E, de repente, uma constatação que me apaziguou. Não havia um menino em mim, não havia nenhum homem dentro de mim. [...] Naquele momento, sob o olhar daquela moça, me dei permissão pela primeira vez. Sim, eu podia me encantar por alguém e esse alguém podia ser uma mulher. Eu podia desejar a minha semelhante, tanto quanto outras semelhantes minhas desejam um homem. (EVARISTO, 2011, p. 57-58, grifo nosso).

Encontramos momentos de (auto)aceitação compartilhados por Evaristo (2011, p.58, grifo nosso): “[...] busquei novamente o olhar daquela que seria a primeira professora de minha filha e com quem eu aprenderia também a me conhecer, a me aceitar feliz e em paz comigo mesma.” e de (auto)realização: “[...] eu nunca tinha sido de ninguém em oferecimento, assim como corpo algum tinha sido meu como dádiva. Só Miríades eu tive. Só Miríades me teve” e "[t]amanha foi a nossa felicidade. Miríades, Walquíria e eu. Minha menina, se pai não teve, de mãe, o carinho foi em abundância, em dose dupla." 
Notamos que a escrita de Evaristo acaba por se configurar como uma proposta de positivizar e enaltecer para dignificar personagens que, historicamente, sempre foram colocadas à margem e quando estavam presentes na literatura canônica eram sempre tratadas com menosprezo, ridicularizadas, condenadas e colocadas no ostracismo. (Re)significar para dignificar.

Evaristo opta por nos presentear com uma bela história de amor, com direito a final feliz entre duas mulheres, sendo uma explicitamente negra, insurgindo-se, insubordinando-se e, ainda que traga lágrimas em suas, quase sempre difíceis histórias, estas se configuram e se apresentam quase sempre como insubmissas, como adjetiva a própria autora. Insubmissas porque não cabem, nem se adéquam a normas, regras e molduras, transgridem e dizem não ao secularmente imposto sobre os corpos e sexualidades.

\section{Campo Belo: em busca de uma conclusão}

A narrativa apresentada revela desejos deslocados dos lugares impostos, rigidamente vigiados e acaba por ampliar, para além da "heteronormatividade compulsória" (RICH, 2010), o leque de possibilidades sobre as formas de amar e de desejar e tendem a extrapolar o que é ditado, fixado pela hegemonia. Desta forma, diversifica as fronteiras identitárias, sobretudo de gênero, contribuindo para a (des)construção do imaginário social, binário, preconceituoso e excludente.

A escrita de Evaristo revela-se importante, principalmente, pela quebra com o silêncio sobre performances e atuações hegemônicas e da ordem do patriarcal. A escrita de Evaristo (2011) proporciona, também, novas formas de pensar, conceber e vivenciar experiências diversas, agora calcadas no respeito, na dignidade e na positivização, sobretudo das personagens.

Essa escrita, aqui denominada de lesboafetiva borra, rasura, bem aos moldes de Derrida (2001), os contornos do esquema construído e pautado na lógica patriarcal, desestabiliza o cânon e as ideologias presentes, desloca e amplia a lógica binária, questiona, interroga identidades consideradas como "clássicas" e dominantes, procurando reverter os efeitos dos tratamentos, predominantemente, negativos, depreciativos, estereotipados e estigmatizantes para com aquelas que ousam romper com o normativo.

As mulheres negras, lésbicas, ou não, quando elegem a lesbotextualidade e a lesboeroticidade como forma de escrita explicitam corpos e histórias tratados até então como abjetos (BUTLER, 2003) para cenários que as tratam com o devido respeito e dignidade merecidos, não mais um lugar de inferioridade e de repulsa. Acabam, dessa maneira, questionando e tensionando a normatividade e o "falo-logo-fonocentrismo" (DERRIDA, 2001).

Criam-se novas formas e possibilidades de se dizer para (re)compor-se, (re)editar-se para si e para o mundo, concretizando processos de (des)naturalização, (des)humanização e (des)animalização de todos aqueles que ousam romper com o normativo. Tudo isso resulta num contra imaginário e dissonâncias, ou seja, não mais submissão à regulação dessas sexualidades, eis os ganhos para tal literatura: (re)significar para dignificar o até então discriminado, 
desvalorizado.

O que se deseja é que os aprendizados adquiridos a partir da escrita preta e lésbica dessa autora possam proporcionar a descoberta das delícias de ser como se é e que não sejamos mais coagidas a desejar o que, compulsoriamente, nos impõem ou internalizarmos a hipersexualidade e/ou animalização impostas a essa corporalidade negra, historicamente reforçadas e legitimadas. Caminhemos, pois, na direção contrária a até então apresentada, imposta e nos permitamos a (auto)apresentação e representação, escolhendo e estabelecendo as cores, nuances e contornos para nossos corpos e existências.

\section{Referências}

AUGUSTO, Geri. A língua não deve nos separar! Reflexões para uma Práxis Negra Transnacional de Tradução. In: CARRASCOSA, Denise. Traduzindo no Atlântico Negro: Cartas Náuticas Afrodiaspóricas para Travessias Literárias. Salvador: Ogums Toques Negros, 2017. p. 31-60.

BUTLER, Judith. Problemas de gênero: feminismo e subversão da identidade. Rio de Janeiro: Civilização Brasileira, 2003.

CARRASCOSA, Denise. Traduzindo no Atlântico Negro: Cartas Náuticas Afrodiasporícas para Travessias Literárias. Salvador: Ogums Toques Negros, 2017.

CARRASCOSA, Denise. Pós-colonialidade, pós-escravismo, bioficção e com(tra)temporaneidade. Estudos de Literatura brasileira contemporânea, Brasília, n. 44, p. 105-124, jul./dez. 2014. Disponível em: http://www.scielo.br/pdf/elbc/n44/a06n44.pdf. Acesso em: 06/07/2017.

CUTI, [Luiz Silva]. Literatura Negro-brasileira. São Paulo: Selo Negro, 2010.

DERRIDA, Jacques. Mal de arquivo: uma impressão freudiana. Rio de janeiro: RelumeDumará, 2001.

DIAS, Camila Sodré de Oliveira. Por uma Literatura das Ausências e das Emergências: as afrolésbicas na escrita de Miriam Alves e Zula Gibi. In: ABRALIC - Experiências Literárias Textualidades Contemporâneas, 15, Rio de Janeiro, RJ. ANAIS. Rio de Janeiro: ABRALIC. 2016. p. 2099-2109. Disponível em: http://www.abralic.org.br/anais/arquivos/2016_1491264573.pdf. Acesso em: 31/03/2019.

EVARISTO, Conceição. Não nasci rodeada de livros, mas de palavras, através da literatura oral. Entrevista. Jornal El país. Paraty. 03 jul. 2017. Disponível em: https://brasil.elpais.com/brasil/2017/07/29/cultura/1501282581_629505.html. Acesso em: 10/01/2019.

EVARISTO, Conceição. História de leves enganos e parecenças. Rio de Janeiro: Malê, 2016.

EVARISTO, Conceição. Olhos d'água. Rio de Janeiro: Pallas, Fundação Biblioteca Nacional, 2014.

EVARISTO, Conceição. Isaltina Campo Belo. In: CONCEIÇÃO, Evaristo. Insubmissas lágrimas de mulheres. Belo Horizonte: Nandyala, 2011. p. 48-58. 
EVARISTO, Conceição. Da grafia-desenho de minha mãe, um dos lugares de nascimento de minha escrita. In: ALEXANDRE, Marcos Antônio (Org.). Representações performáticas brasileiras: teorias, práticas e suas interfaces. Belo Horizonte: Mazza, 2007. p. 16-21.

EVARISTO, Conceição. Da representação a auto-representação da mulher negra da mulher negra na literatura brasileira. Revista Palmares: cultura afro-brasileira. Brasília, v.1, n. 1, p. 5254, ago. 2005. Disponível em: http://www.palmares.gov.br/wpcontent/uploads/2011/02/revista01.pdf. Acesso em: 31 mar. 2019.

EVARISTO, Conceição. Ponciá Vicêncio. Belo Horizonte: Mazza Edições, 2003.

FONSECA, Maria Nazareth Soares. Literatura Negra, Literatura Afro-brasileira: como responder a polêmica. In: SOUZA, Florentina; LIMA, Maria Nazaré. Literatura afrobrasileira. Salvador: CEAO, 2006. p. 9-38.

GIRAUDO, José Eduardo Fernandes. Poética da memória: uma leitura de Toni Morrison. Porto Alegre: UFRGS, 1997.

GLISSANT, Édouard. A barca aberta. In: GLISSANT, Édouard. Poética da Relação. Porto: Sextante Editora, 2011. p. 17-20.

GLISSANT, Édouard. The open boat. In: GLISSANT, Édouard. Poetics of relation. The Michigan: University of Michigan Press. 2010. p. 5-10.

GLISSANT, Édouard. Introdução a uma poética da diversidade. Juiz de Fora: Editora UFJF, 2005.

GILROY, Paul. O Atlântico Negro. Modernidade e dupla consciência. São Paulo, Rio de Janeiro: Editora 34: UCAM, 2001.

HAESBAERT, Rogério. O mito da desterritorialização: do "fim dos territórios" à multiterritorialidade. 3. ed. Rio de Janeiro: Bertrand Brasil, 2007.

hooks, bell. O amor como prática da liberdade. [Tradução para uso didático por Wanderson Flor Nascimento]. Disponível em: https://medium.com/enugbarijo/o-amor-como-apr\%C3\%A1tica-da-liberdade-bell-hooks-bb424f878f8c. Acesso em: 08/08/2017. In: hooks, bell. Outlaw Culture: Resisting Representations. New York: Routledge, 2006, p. 243-250.

hooks, bell. Vivendo de Amor. In: WERNECK, Jurema (Org.). O Livro da Saúde das Mulheres Negras: nossos passos vêm de longe. Rio de Janeiro: Pallas/Criola, 2000, p. 188-198.

LEVANTES LITERÁRIOS. Disponível em: https://correionago.com.br/portal/dialogospresentes-cris-sales-entrevista-poeta-cuti/. Acesso em: 02/10/2017.

LORDE, Audre. A transformação do silêncio em linguagem e ação. Geledés. Rio de Janeiro. 2015. Disponível em: https://www.geledes.org.br/a-transformacao-do-silencio-em-linguageme-acao/. Acesso em: 20/08/2017.

LORDE, Audre. Sister outsider: essays and speeches. New York: Crossing Press. Crossing Press Feminist Series, 2007. 
LORDE, Audre. Espelhos não são baratos. [Textos escolhidos de Audre Lorde] Projeto Raiz Forte. Vitória: Edições Feministas e Lésbicas independentes. Disponível em: http://www.projetoraizforte.com.br/biblioteca/textos-escolhidos-de-audre-lorde/. Acesso em: 04/04/2017. In: LORDE, Audre. Good mirrors are not cheap. In: LORDE, Audre. The collected poems of Audre Lorde. New York: Norton \& Company, 2000, p. 73.

LORDE, Audre. In: TATE, C. (Org.). Black Women Writers at Work. New York: Continuum, 1983. p. 100-116.

NASCIMENTO, Tatiana. Audre Lorde, Dionne Brand. Entrevista - Vídeo Youtube. Projeto Literatura Inteira. Salvador, n. 5 2017. Disponível em: https://www.youtube.com/watch?v=mHUo9M5KI5k\&t=834s. Acesso em: 29/03/2019.

RICH, Adrienne. A heterossexualidade compulsória e existência lésbica. Revista Bagoas. Natal, n. 5, p. 17-44, 2010. Disponível em: http://www.cchla.ufrn.br/bagoas/. Acesso em: 02/08/2017.

RISO, Ricardo. É hora de ouvir os atabaques de dois poetas sem equívocos: Éle Semog e José Carlos Limeira. Liteafro. s/d. Disponível em: http://www.letras.ufmg.br/literafro/. Acesso em: $13 / 08 / 2017$.

SALES, Cristian Souza de. Conto Regina Anástácia. Palestra Diálogos insubmissos de mulheres negras. Salvador, 2017.

SAUNDERS, Tanya L. Epistemologia negra sapatão como vetor de uma práxis humana libertária. Tradução de: Sarah Ryanne Sukerman Sanches. Periódicus, Salvador, n. 7, v. 1, p. 102-116, mai./out,, $2017 . \quad$ Disponível em: https://portalseer.ufba.br/index.php/revistaperiodicus/article/view/22275. Acesso em: 28/08/2017.

SILVA, Ana Rita. Vozes literárias negras. Cruz das Almas: UFRB, 2012.

SANTOS, Neuza Souza. Torna-se negro: as vicissitudes da identidade do negro brasileiro em ascensão social. Rio de Janeiro: Edições Graal, 1983.

WALKER, Alice. Search of our mothers gardens. In: WALKER, Alice. Search of our Mothers Gardens: Womanist Prose. New York: Harcourt, 1983. p. 231-243.

WALKER, Sheila. Rostos familiares, lugares inesperados: uma diáspora africana global. Documentário. Afrodiáspora Inc, 2018. Disponível em: https://www.youtube.com/watch?v=g1BceeLjIRo. Acesso em: 29/03/2019.

Geny Ferreira Guimarães (genybr@yahoo.com.br) é Professora EBTT de Geografia no CTUR/UFRRJ e Coordenadora do LABGEO/CTUR. Doutora em Geografia - UFBA. Mestre em Ciências Sociais - UFRRJ/CPDA. Formação inicial em Geografia - UFF. Especializações (Lato Sensu) em Relações Internacionais - UCAM (1999) e Gestão para Educação Ambiental - UERJ (2001). Campos de pesquisas envolvem discussões sobre: patrimônios; relações étnicoraciais e antirracistas; Geografia \& Literatura Negro-brasileira e dimensão racial do espaço.

Hildalia Fernandes Cunha Cordeiro (hildaliafernandes@hotmail.com) é doutoranda em Literatura e Cultura pelo ILUFBA; Mestre em Educação e Contemporaneidade pelo 
PPGEDUC/UNEB; Especialista em História e cultura afro-brasileira pela Fundação Visconde de Cairu; Especialista em Linguística com ênfase em Análise do Discurso pelo CEPOM; Licenciada em Pedagogia pela Faculdade D. Pedro II; Bacharel em Serviço Social pela Universidade Católica do Salvador; contista e pesquisadora sobre Escrita literária de mulheres negras diaspóricas.

\section{NOTAS DE AUTORIA}

\section{Como citar esse artigo de acordo com as normas da revista}

GUIMARÃES, Geny Ferreira; CORDEIRO, Hidalia Fernandes Cunha. Campo Belo: narrativa insubmissa e insurgente. Anuário de Literatura, Florianópolis, v. 24, n. 1, p. 131-148, 2019.

\section{Contribuição de autoria}

Geny Ferreira Guimarães: Participou desde a concepção do texto, leituras necessárias para a escrita preliminar, revisões e escrita final, além do atendimento as revisões propostas pela revista. Com contribuições ao longo do texto com alguns elementos da minha área específica de pesquisa.

Hildalia Fernandes Cunha Cordeiro: Participou desde a concepção do texto, leituras necessárias para a escrita preliminar, revisões e escrita final, além do atendimento as revisões propostas pela revista. Com inserções de algumas especificidades da minha área de pesquisa.

\section{Financiamento}

O presente trabalho foi realizado com apoio da Coordenação de Aperfeiçoamento de Pessoal de Nível Superior - Brasil (CAPES) - Código de Financiamento 001.

\section{Consentimento de uso de imagem}

Não se aplica.

\section{Aprovação de comitê de ética em pesquisa}

Não se aplica.

\section{Licença de uso}

Este artigo está licenciado sob a Licença Creative Commons CC-BY. Com essa licença você pode compartilhar, adaptar, criar para qualquer fim, desde que atribua a autoria da obra.

\section{Histórico}

Recebido em: 31/03/2019

Revisões requeridas em: 30/06/2019

Aprovado em: 15/07/2019

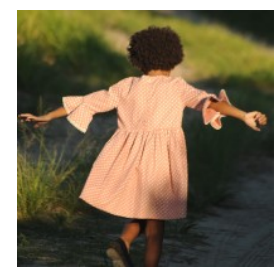

